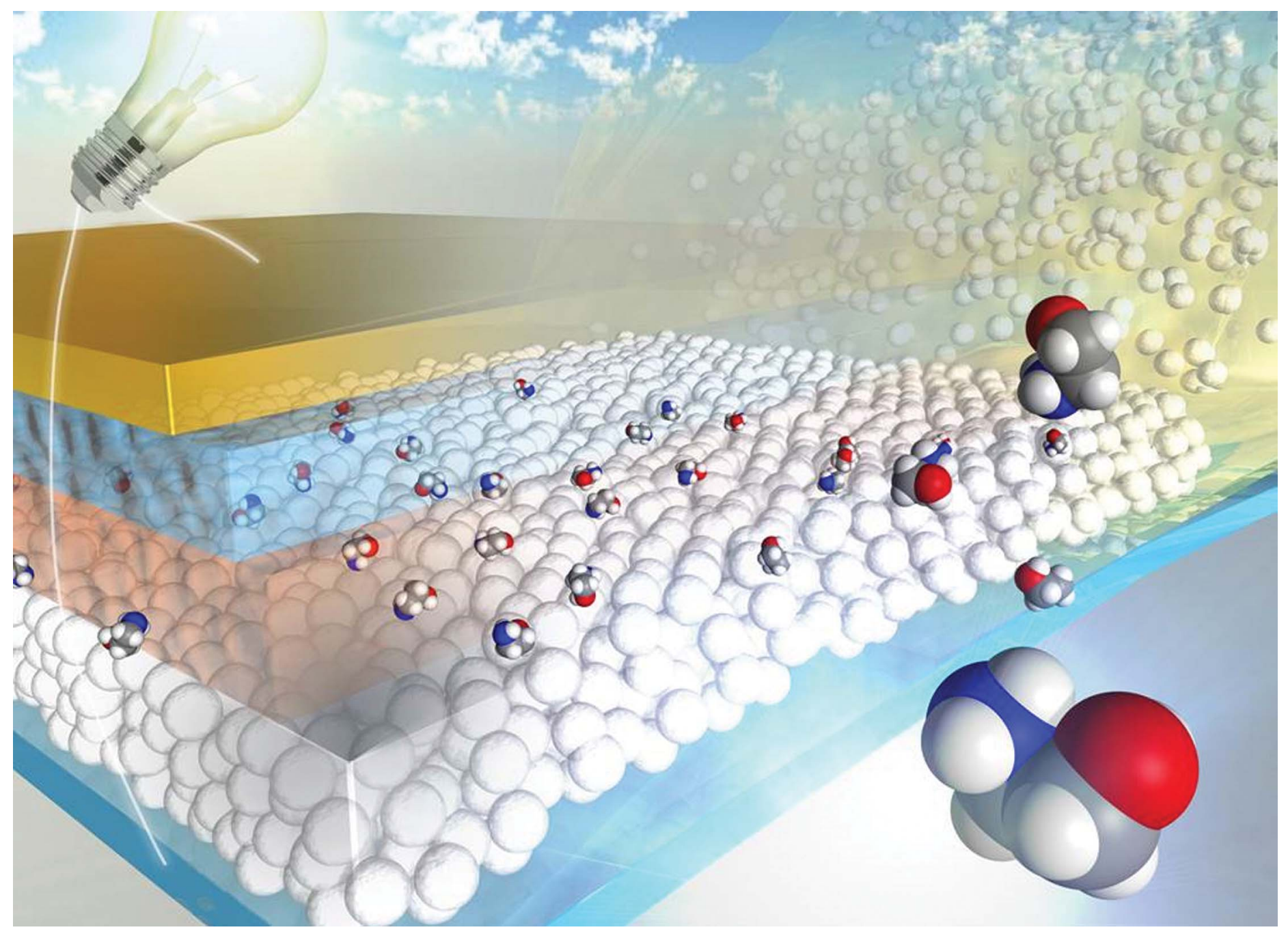

A graphical illustration of using 2-aminoethanol in $\mathrm{ZnO}$ nanoparticles synthesis for organic solar cell application by Prof. Yutaka Matsuo at the Department of Chemistry, School of Science, the University of Tokyo.

Title: Air-processed inverted organic solar cells utilizing a 2-aminoethanol-stabilized $\mathrm{ZnO}$ nanoparticle electron transport layer that requires no thermal annealing

Well-dispersed ZnO nanoparticles using 2-aminoethanol as both the stabilizer and solvent enable the formation of an electron transport layer in inverted organic solar cells without any thermal annealing.
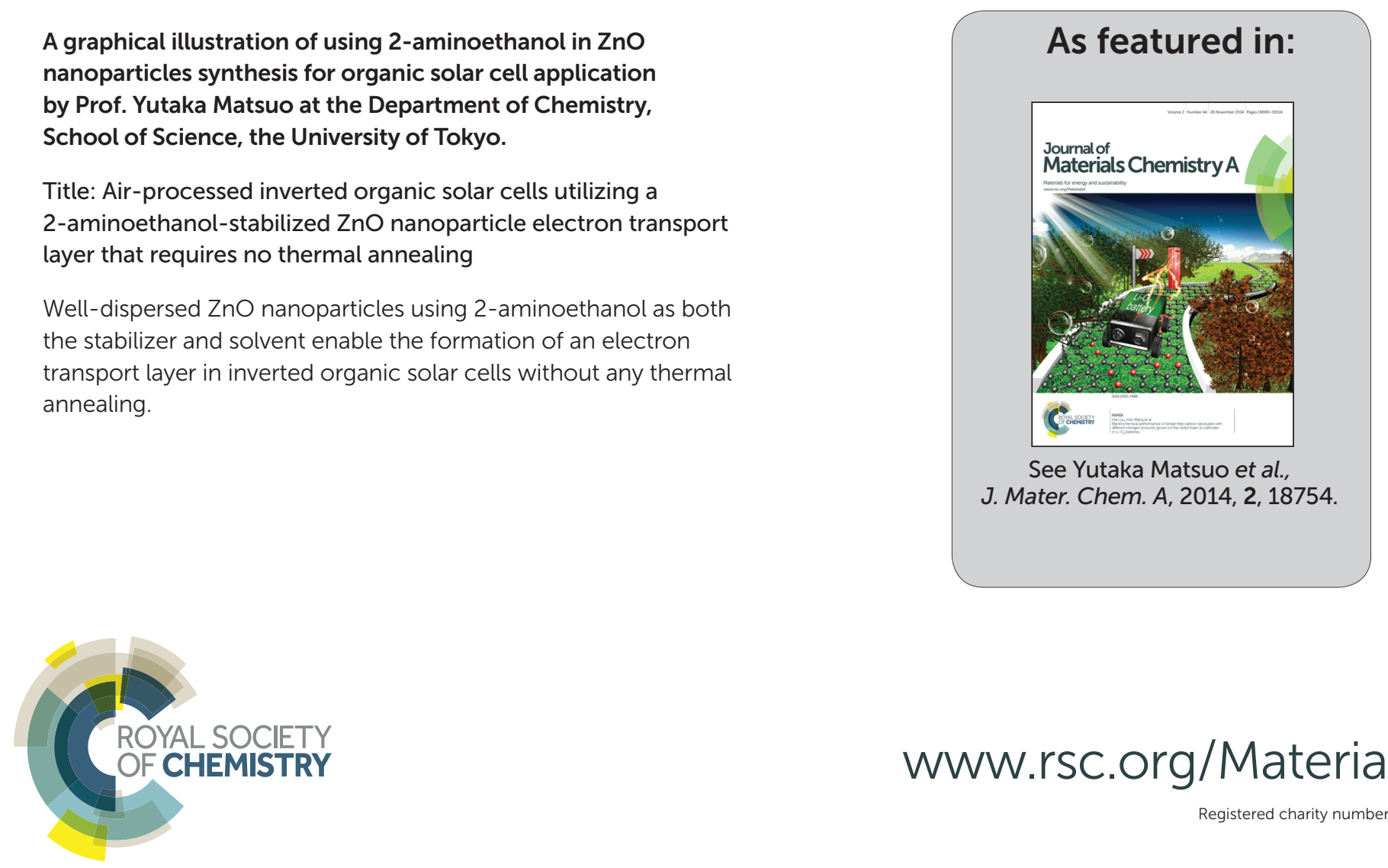


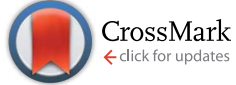

Cite this: J. Mater. Chem. A, 2014, 2 , 18754

Received 4th September 2014

Accepted 4th September 2014

DOI: $10.1039 / c 4 t a 04595 e$

www.rsc.org/MaterialsA

\section{Air-processed inverted organic solar cells utilizing a 2-aminoethanol-stabilized ZnO nanoparticle electron transport layer that requires no thermal annealing $\dagger$}

\author{
Il Jeon, ${ }^{a}$ James W. Ryan, ${ }^{\text {T Tafu Nakazaki, }}$ Kee Sheng Yeo, ${ }^{a}$ Yuichi Negishib \\ and Yutaka Matsuo*a
}

Highly stable ZnO nanoparticles (NPs) for use in organic solar cells (OSCs) have been synthesized in 2aminoethanol, which acts as both a stabilizing ligand and a solvent. The ZnO NP films do not require thermal annealing and applying them in inverted P3HT:mix-PCBM OSCs fabricated almost entirely under ambient conditions show efficiencies $>3 \%$. We find that thermally annealing the ZnO NP films does not give rise to any significant differences in device performance up to $150^{\circ} \mathrm{C}$. Annealing the films at higher temperatures leads to reduced short-circuit current densities and fill factors due to the removal of 2aminoethanol from the NP surface, as evidenced by X-ray photoelectron spectroscopy. Furthermore, to confirm that the post-annealing of P3HT:PCBM devices at $150{ }^{\circ} \mathrm{C}$ does not affect our results, we fabricated inverted small molecule OSCs using a squaraine donor and $\mathrm{PC}_{71} \mathrm{BM}$ acceptor that only requires a low-temperature thermal annealing step $\left(70^{\circ} \mathrm{C}\right)$. No substantial differences between annealed and non-annealed devices were observed, which demonstrates the applicability of these new ZnO NPs in flexible OSCs.

\section{Introduction}

Organic solar cells (OSCs) have demonstrated their potential as next-generation light harvesting devices for supplying a significant quota of the world's energy in a clean and efficient manner. ${ }^{1}$ In the past number of years significant advances have been made that have lead to OSC efficiencies reaching $10 \% .^{2}$ As efficiencies continue to increase so does the need for industrial considerations to be addressed, such as improving device stability and lowering fabrication costs. ${ }^{3}$ In a normal architecture OSC, the device relies on the use of a low work function top electrode that is highly susceptible to degradation from oxygen and water, as are many of the organic materials that make up the active and interfacial layers. The final steps of device fabrication must therefore be carried out under dry anaerobic conditions and, prior to exposing the device to ambient conditions, a potentially costly encapsulation layer must be incorporated. Inverting the architecture, however, allows the use of high work function electrodes such as silver and gold, as well as

${ }^{a}$ Department of Chemistry, School of Science, The University of Tokyo, 7-3-1 Hongo, Bunkyo-ku, Tokyo 113-0033, Japan. E-mail: matsuo@chem.s.u-tokyo.ac.jp

${ }^{b}$ Department of Applied Chemistry, Tokyo University of Science, 1-3 Kagurazaka, Shinjuku, Tokyo 162-8601, Japan

$\dagger$ Electronic supplementary information (ESI) available: TEM images of ZnO NPs, wide-scan XPS spectra for each sample, and device performance of $\mathrm{ZnO}$ in ethylene glycol based solar cells. See DOI: 10.1039/c4ta04595e air-stable metal oxide transport layers, which provide added protection to the active layer. ${ }^{4} \mathrm{MoO}_{3}$ is typically employed as the hole transport layer (HTL) for reducing Ohmic losses between the donor's HOMO and the Au or Ag anode. ${ }^{4 a, 5}$ PEDOT:PSS can also be utilized as the HTL, having the advantage of being easily deposited via spin-coating on top of the active layer. ${ }^{6}$ The most common electron-transport materials are $\mathrm{ZnO}$ and $\mathrm{TiO}_{2}$, which offer high electron transport between the fullerene and the ITO interface. ${ }^{7}$ However one common drawback does exist with these materials, which is that a high temperature step is required. For most deposition methods of $\mathrm{ZnO}$ and $\mathrm{TiO}_{2}$ films annealing temperatures in excess of $150{ }^{\circ} \mathrm{C}$ are generally required, ${ }^{4 b, 7 a}$ which is well above the glass transition temperature of common polymeric substrates used in flexible organic electronic devices. During the preparation of this manuscript, $\mathrm{Lu}$ and Tao et al. reported a method for depositing $\mathrm{ZnO}$ films that does not require thermal annealing, using an air-sensitive ZnO NP solution. ${ }^{8}$ Here, we demonstrate a new and facile synthesis route for obtaining highly stable $\mathrm{ZnO}$ nanoparticle (NP) solutions for fabricating low-temperature $\mathrm{ZnO}$ films that can be applied as ETLs in OSCs. The NPs are synthesized in 2aminoethanol and do not require any additional stabilizers or ligands, aside from the solvent molecules themselves. Furthermore, the ZnO films can be readily processed in air. Inverted OSCs were fabricated with the ZnO NP films subjected to various annealing temperatures, where the active layer was 
P3HT:mix-PCBM, mix-PCBM corresponds to a mixture of $\mathrm{PC}_{61} \mathrm{BM}(85 \mathrm{wt} \%)$ and $\mathrm{PC}_{71} \mathrm{BM}(15 \mathrm{wt} \%)$ that is more economical and has been shown to offer higher stability and slightly higher performance than pure $\mathrm{PC}_{61} \mathrm{BM} .{ }^{9} \mathrm{X}$-ray photoelectron spectroscopy and atomic force microscopy are employed to study the surface chemistry and topography, respectively. Inverted small molecular OSCs (SMOSCs) using the ZnO NP films are also investigated, based on a squaraine (SQ) donor and a $\mathrm{PC}_{71} \mathrm{BM}$ acceptor, to demonstrate the potential of this approach for fabricating low-temperature OSCs compatible with flexible substrates. ${ }^{7 d}$

\section{Results and discussion}

The synthesis of the ZnO NPs is similar to the method used by Lin et al.,$^{10}$ where we replaced diethylene glycol with a shorter alkyl chained amino alcohol, 2-aminoethanol. The use of 2aminoethanol allowed a more concentrated solution to be obtained compared with the previous method. The synthesis and isolation of the ZnO NPs is shown in Scheme 1, which consisted of heating zinc acetate $(\mathrm{ZnOAc})_{2}$ in 2-aminoethanol to $160{ }^{\circ} \mathrm{C}$ and refluxing for an hour.

Once the solution was cooled down, it was centrifuged, which led to a precipitate that contained ZnO NPs with diameters in excess of $100 \mathrm{~nm}$ and a pale yellow supernatant that provided well dispersed ZnO NPs with a mean diameter of 2.5 $\mathrm{nm}$ as determined by transmission electron microscopy (see ESI Fig. S1-1†). The concentration of the solution obtained was 0.24 $\mathrm{mg} \mathrm{ml} \mathrm{m}^{-1}$ and stable for at least 6 months, which, considering that no additional stabilizing ligands were required in addition to the 2-aminoethanol solvent molecules, is an interesting and important finding.

The as-obtained supernatant solution was then used in fabricating OSCs by spin-coating it on indium tin oxide (ITO) patterned glass substrates. Following spin-coating, the films were then subjected to thermal annealing at temperatures ranging from room temperature (i.e. no annealing) to $210{ }^{\circ} \mathrm{C}$. The annealing time was fixed at $1 \mathrm{~h}$ in each case. The transmittance of the $\mathrm{ZnO}$ thin films on glass/ITO substrates are shown in Fig. 1 and shows a decrease in transmittance with

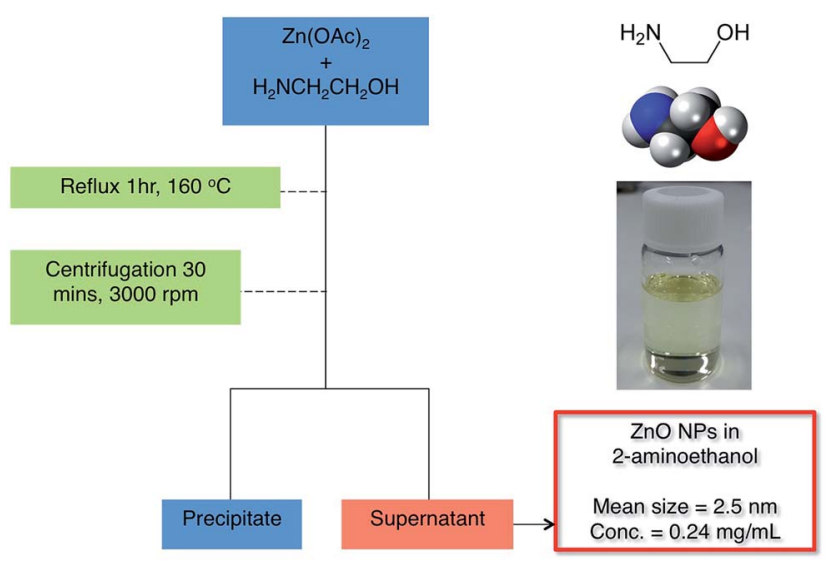

Scheme 1 Synthesis and separation of $\mathrm{ZnO}$ nanoparticles.

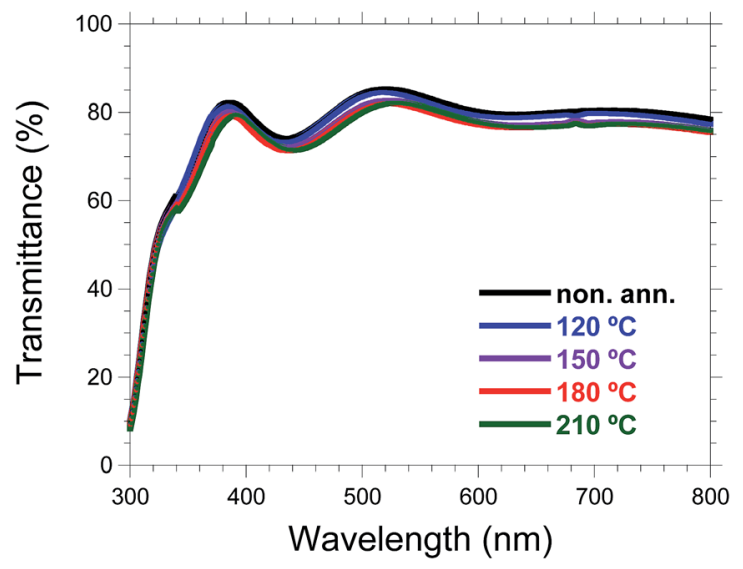

Fig. 1 Transmittance spectra of ZnO NP films on glass/ITO substrates annealed at different temperatures.

annealing temperature. Non-annealed ZnO NP films show the highest transmittance, with a maximum transmittance of $85.2 \%$ at $520 \mathrm{~nm}$.

P3HT:mix-PCBM active layers were then deposited, followed by a PEDOT:PSS hole transport layer and Au electrode. Note that all layers, except for gold, were deposited in air. Furthermore, devices were also annealed and measured in air, without the addition of an encapsulation layer, demonstrating the good stability of these inverted devices. The current-voltage $(J-V)$ curves of the OSCs are shown in Fig. 2 and Table 1 summarizes the key figures of merit. Remarkably, devices processed without subjecting the ZnO layer to any thermal annealing have the highest power conversion efficiency (PCE, $\eta$ ) of $3.1 \%$ due to the higher fill factor (FF) compared with the annealed devices. Although, the difference between the devices with nonannealed $\mathrm{ZnO}$ films and the devices annealed up to $120^{\circ} \mathrm{C}$ do not in fact differ considerably. There is, however, a significant difference in $\eta$ when the annealing temperature exceeds $120^{\circ} \mathrm{C}$, where the FF decreases with increasing temperature as does the short-circuit current density $\left(J_{\mathrm{SC}}\right)$, with a significant drop observed when annealing exceeds $150{ }^{\circ} \mathrm{C}$. This decrease in FF arises from an increase in series resistance $\left(R_{\mathrm{S}}\right)$ as well as the shunt resistance $\left(R_{\mathrm{Sh}}\right)$, with values decreasing with annealing temperature (see Table 1). S-shaped curves are observed for devices employing $\mathrm{ZnO}$ films annealed at $210{ }^{\circ} \mathrm{C}$, which further decreases the FF. The origin of the S-shaped kink in the $J-V$ curve is not entirely clear but probably arises from $\mathrm{ZnO}$ inducing a barrier to charge injection or extraction. ${ }^{11}$ Considering that 2-aminoethanol should have been removed from the ZnO NP surface due to the high annealing temperature (at least for the NPs on the ZnO surface), we would expect the NPs to have a high concentration of trap states that may reduce the conductivity of the $\mathrm{ZnO}$ film as well as act as trap-sites for free charge carriers generated in the active layer. All devices displayed a short UV-activation time, i.e. light soaking, but there was no noticeable trend between the activation time and the annealing conditions. Reference P3HT:mix-PCBM inverted devices were also fabricated for comparison using a standard sol-gel method to deposit the ZnO film (thermally annealed at 
(a)

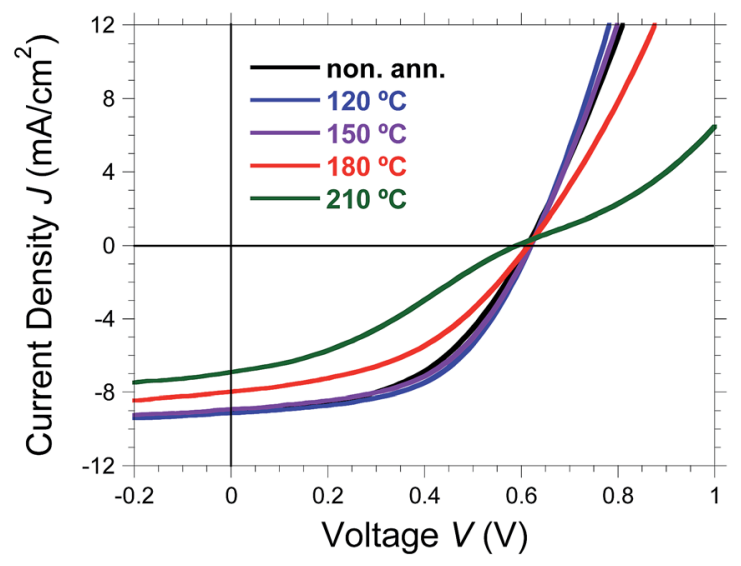

(b)

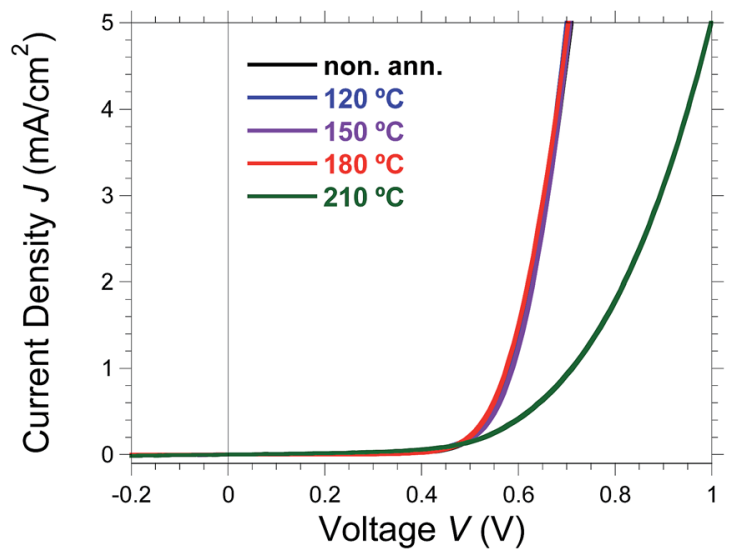

Fig. 2 J-V curves for inverted P3HT:mix-PCBM devices where the ZnO NP film was subject to various annealing temperatures measured under (a) 1 Sun illumination (AM $1.5 \mathrm{G}, 100 \mathrm{~mW} \mathrm{~cm}{ }^{-2}$ ) and (b) dark conditions. Non-annealed (black), $120{ }^{\circ} \mathrm{C}$ (blue), $150{ }^{\circ} \mathrm{C}$ (purple), $180^{\circ} \mathrm{C}$ (red) and $210^{\circ} \mathrm{C}$ (green).

$\left.200{ }^{\circ} \mathrm{C}\right),{ }^{4 b}$ which shows slightly higher but not significantly different performance $(\eta=3.2 \%)$, demonstrating the high applicability of our ZnO NP approach in OSCs. We have fabricated devices using ZnO NPs synthesized in ethylene glycol and found that they do not perform as well as ZnO NPs in 2-aminoethanol. (see ESI Fig. S3†) We attribute this to the larger diameter of the ZnO NPs (4.09 $\mathrm{nm}$ on average) that also display a larger size deviation than the ZnO NP in 2-aminoethanol (see also ESI Fig. S1-2†).

Investigating the effect of thermal annealing on the thin film properties of $\mathrm{ZnO}$, we found that the topography, as measured by atomic force microscopy (AFM) on ITO/Glass substrates, did not change significantly with rms roughness values between 5 and $6 \mathrm{~nm}$ (Fig. 3). Non-annealed films had the roughest topography and it can be seen that upon annealing at $120{ }^{\circ} \mathrm{C}$, the roughness decreases and then increases with temperature. The changes are subtle, however, and are probably not significant enough to explain the large changes in the $J-V$ characteristics.

The surface chemistry of the ZnO films was then probed using X-ray photoelectron spectroscopy (XPS). Fig. 4 shows the peaks of ZnO films corresponding to (a) $\mathrm{Zn} 2 \mathrm{p}_{3 / 2}$ and (b) $\mathrm{N} 1 \mathrm{~s}$ core levels (refer to the ESI $\uparrow$ for the wide-scan images of each film). A positive shift in the binding energy (BE) of $\sim 1 \mathrm{eV}$ is observed for both $\mathrm{Zn} 2 \mathrm{p}_{3 / 2}$ and $\mathrm{N}$ 1s peaks when the films are annealed at $150{ }^{\circ} \mathrm{C}$ and above. This increase in BE for both $\mathrm{Zn}$ and $\mathrm{N}$ indicates that 2-aminoethanol is cleaved from the surface of the ZnO NPs. Furthermore, the intensity of the 2-aminoethanol peaks is seen to decrease with annealing temperature, even for the films annealed at $120^{\circ} \mathrm{C}$, which is much lower than the boiling point of 2-aminoethanol $\left(170{ }^{\circ} \mathrm{C}\right)$. The $\sim 1 \mathrm{eV}$
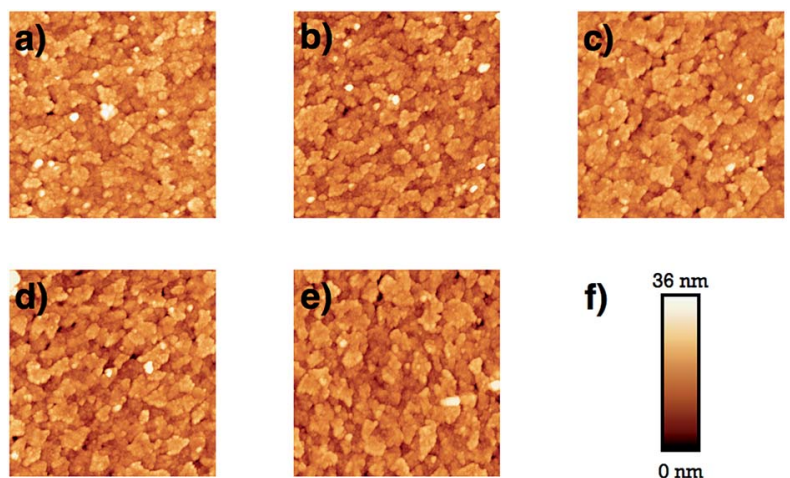

Fig. 3 Atomic force microscopy topography images of ZnO NP thin films corresponding to the following annealing conditions: (a) nonannealed, (b) $120^{\circ} \mathrm{C}$, (c) $150{ }^{\circ} \mathrm{C}$, (d) $180^{\circ} \mathrm{C}$ and (e) $210^{\circ} \mathrm{C}$. The area scanned for each image was $5 \times 5 \mu \mathrm{m}$ and (f) the $Z$-scale for each image is also identical.

Table $1 \mathrm{~J}-V$ characteristics of P3HT:mix-PCBM devices recorded under 1 Sun illumination (100 $\left.\mathrm{mW} \mathrm{cm}^{-2}, \mathrm{AM} 1.5 \mathrm{G}\right)$ and resistance values obtained from dark $J-V$ curves

\begin{tabular}{|c|c|c|c|c|c|c|}
\hline Annealing temperature & $V_{\mathrm{OC}} \mathrm{V}$ & $J_{\mathrm{SC}} \mathrm{mA} \mathrm{cm}^{-2}$ & $\mathrm{FF}$ & $\eta \%$ & $R_{\mathrm{S}} \Omega \mathrm{cm}^{2}$ & $R_{\mathrm{Sh}} \Omega \mathrm{cm}^{2}$ \\
\hline NA & 0.61 & 9.08 & 0.56 & 3.1 & 8.29 & 1660 \\
\hline $120^{\circ} \mathrm{C}$ & 0.62 & 9.13 & 0.53 & 3.0 & 8.43 & 1540 \\
\hline $150^{\circ} \mathrm{C}$ & 0.62 & 8.65 & 0.53 & 2.9 & 8.35 & 1270 \\
\hline $180^{\circ} \mathrm{C}$ & 0.61 & 7.98 & 0.45 & 2.2 & 9.77 & 1220 \\
\hline $210^{\circ} \mathrm{C}$ & 0.59 & 6.91 & 0.34 & 1.4 & 20.11 & 1120 \\
\hline $200{ }^{\circ} \mathrm{C}^{a}$ & 0.60 & 9.42 & 0.56 & 3.2 & 5.71 & 2230 \\
\hline
\end{tabular}

${ }^{a}$ Sol-gel reference devices. 
(a)

increase in $\mathrm{BE}$ for both $\mathrm{Zn}$ and $\mathrm{N}$ does not exactly reflect the trend observed in the $J-V$ curves above, as the device employing a ZnO film annealed at $150^{\circ} \mathrm{C}$ still has relatively high efficiency even though 2-aminoethanol has been cleaved from the $\mathrm{ZnO}$ surface. However, when the films are annealed at temperatures above the boiling point of 2-aminoethanol we do see a significant decrease in the performance. These results suggest that the presence of 2-aminoethanol is important. Indeed, a recent study on a polar solvent treatment of rippled-ZnO films by Song and co-workers has shown that treating the metal oxide film with a solution of 2-methoxyethanol and just 1\% 2-aminoethanol enhances the electrical contact between the $\mathrm{ZnO}$ and the LUMO of PCBM. ${ }^{12}$

The spectra for the $\mathrm{O} 1 \mathrm{~s}$ core level are shown in Fig. 5, which correspond to the $\mathrm{O}$ in $\mathrm{ZnO}$. We observe an asymmetric peak for each sample that was deconvoluted using curve-fitting methods into two peaks centered at $529.7 \pm 0.5 \mathrm{eV}(\mathrm{O} 1)$ and $531.1 \pm 0.5$ $\mathrm{eV}(\mathrm{O} 2)$ that correspond to $\mathrm{O}^{2-}$ ions of the $\mathrm{Zn}-\mathrm{O}$ bond for the $\mathrm{ZnO}$ wurtzite structure and oxygen deficient component of $\mathrm{ZnO}$ where $\mathrm{O}^{2-}$ ions correspond to the hydroxyl groups, respectively. ${ }^{13}$ The ratio of $\mathrm{O} 1: \mathrm{O} 2$ is seen to change with annealing temperature. $\mathrm{O} 1$ is slightly more dominant in the non-annealed

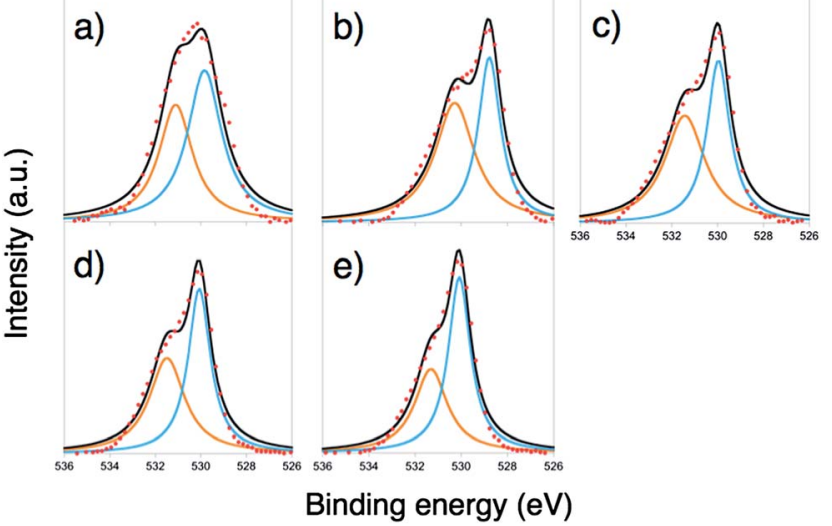

Fig. 5 XPS spectra of the $\mathrm{O}$ 1s peaks of the $\mathrm{ZnO}$ films under the following annealing conditions: (a) non-annealed, (b) $120{ }^{\circ} \mathrm{C}$, (c) $150{ }^{\circ} \mathrm{C}$, (d) $180^{\circ} \mathrm{C}$ and (e) $210^{\circ} \mathrm{C}$. The orange and blue fits correspond to the deconvoluted $\mathrm{O}^{2-}$ species, the former being an oxygen deficient species and the latter peak consistent with that of $\mathrm{O}^{2-}$ in a perfect wurtzite crystal. The raw data are represented by red circles along with best fits shown as a black line.

$\mathrm{ZnO}$ film $(\mathrm{O} 1: \mathrm{O} 2=55: 45)$. Upon annealing at $120{ }^{\circ} \mathrm{C}$ in air, $\mathrm{O} 2$ is the slightly more dominant species $(48: 52)$. However, the percentage of $\mathrm{O} 2$ recorded for films heated at higher temperatures proceeds to decrease with temperature. For films annealed at $210{ }^{\circ} \mathrm{C}$ the $\mathrm{O} 1: \mathrm{O} 2$ ratio is $60: 40$. It is difficult to correlate these data with the experimental $J-V$ curves, as one would expect a decrease of hydroxyl groups to correlate with a decrease in the number of trap states and thus better performance, particularly concerning the FF. The opposite trend until $120^{\circ} \mathrm{C}$ is observed, however, due to the removal of 2-aminoethanol. It could be possible that the $\mathrm{OH}$ group of 2-aminoethanol is also partially responsible for the peaks centered at $531 \mathrm{eV}$.

While a clear trend in device performance with $\mathrm{ZnO}$ annealing temperature is observed, it must be remembered that the device undergoes a post-annealing process at $150{ }^{\circ} \mathrm{C}$ to improve the active layer morphology, which may anneal $\mathrm{ZnO}$ in the process and affect the surface chemistry of the ZnO NPs. Therefore, to minimize the influence of the device annealing temperature, we fabricated inverted small molecule organic solar cells (SMOSCs) that only require the active layer to be annealed at $70{ }^{\circ} \mathrm{C}$ based on a squaraine donor, 2,4-bis $[4-(N, N$ diisobutylamino)-2,6-dihydroxyphenyl] squaraine (SQ) ${ }^{14}$ and a $\mathrm{PC}_{71} \mathrm{BM}$ acceptor. ${ }^{15}$ Active layers were prepared by spin-coating a $20 \mathrm{mg} \mathrm{ml}{ }^{-1}$ solution of $\mathrm{SQ}: \mathrm{PC}_{71} \mathrm{BM}$ in chloroform; the donor : acceptor ratio was $1: 5$ (see the Experimental section for a detailed description of device fabrication). Fig. 6 shows the $J-V$ curves recorded under standard 1 Sun illumination conditions for devices using non-annealed $\mathrm{ZnO}$ NP films as well as films annealed at $120^{\circ} \mathrm{C}$ and $150^{\circ} \mathrm{C}$. We observed very little difference between the device characteristics, with PCEs of approximately $3 \%$ (see Table 2). While the FF for each device is low, it does not differ significantly to what is reported for normal-architecture SQ:PC ${ }_{71} \mathrm{BM}$ devices, which generally have FFs between 40 and $45 \%{ }^{15,16}$ We expect that through optimizing device fabrication, higher PCE can be achieved. However, the main focus here is 


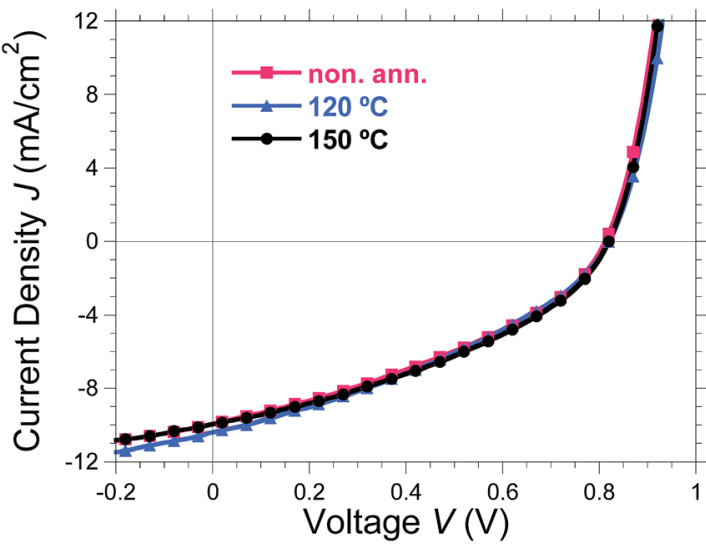

Fig. $6 \mathrm{~J}-V$ curves under 1 Sun illumination (AM $1.5 \mathrm{G}, 100 \mathrm{~mW} \mathrm{~cm}{ }^{-2}$ ) for inverted $S Q: P C_{71} B M$ devices where the $Z n O N P$ film was annealed at $120{ }^{\circ} \mathrm{C}$ (blue, triangles) and $150{ }^{\circ} \mathrm{C}$ (black, circles) as well as nonannealed (pink, squares).

Table $2 J-V$ characteristics of $S Q: P C_{71} B M$ devices recorded under 1 Sun illumination (100 $\mathrm{mW} \mathrm{cm}^{-2}$, AM $\left.1.5 \mathrm{G}\right)$

\begin{tabular}{lcccc}
$\begin{array}{l}\text { Annealing } \\
\text { temperature }\end{array}$ & $V_{\mathrm{OC}} \mathrm{V}$ & $J_{\mathrm{SC}} \mathrm{mA} \mathrm{cm}^{-2}$ & $\mathrm{FF}$ & $\eta \%$ \\
\hline $\mathrm{NA}$ & 0.84 & 9.74 & 0.36 & 3.0 \\
$120^{\circ} \mathrm{C}$ & 0.82 & 10.41 & 0.36 & 3.0 \\
$150{ }^{\circ} \mathrm{C}$ & 0.82 & 9.96 & 0.38 & 3.1 \\
\hline
\end{tabular}

simply to demonstrate that the ZnO NP films do not require high temperature thermal annealing for efficient OSCs, which is clearly evident in the $J-V$ curves in Fig. 6 .

\section{Conclusions}

We have demonstrated a new route for the synthesis of highly stable and high performance ZnO films for inverted OSCs that requires no thermal annealing. Applying thermal annealing post-deposition was found to severely affect device performance for temperatures above $150{ }^{\circ} \mathrm{C}$, due to the desorption of 2aminoethanol from the ZnO NP surface, as evidenced by XPS. Inverted P3HT:mix-PCBM devices employing the ZnO NP films showed respectable efficiencies of $\sim 3 \%$, which is on par with devices utilizing a conventional $\mathrm{ZnO}$ sol-gel derived ETL. As the P3HT:mix-PCBM devices underwent a post-deposition thermal annealing step at $150{ }^{\circ} \mathrm{C}$, we investigated whether this affected the $\mathrm{ZnO} \mathrm{NP}$ film by fabricating low-temperature SQ: $\mathrm{PC}_{71} \mathrm{BM}$ devices that only required thermal annealing of $70^{\circ} \mathrm{C}$. For these small molecule OSC devices, no significant differences were observed for devices employing non-annealed $\mathrm{ZnO}$ films to those using $\mathrm{ZnO}$ films annealed at temperatures up to $150^{\circ} \mathrm{C}$. The long shelf life of the ZnO NP solution coupled with the ability to form high performance ZnO films is an important finding and we hope that this approach will find applications in not only OSCs but also in other organic and organic-inorganic electronic devices.

\section{Experimental section}

\section{ZnO nanoparticle synthesis}

For the chemical synthesis of $\mathrm{ZnO}$ nanoparticles (NPs) in 2aminoethanol the following commercially available chemicals were used without further purification: zinc(II) acetate, $\mathrm{Zn}\left(\mathrm{CH}_{3} \mathrm{COO}\right)_{2}$ (Wako, 99\%) and 2-aminoethanol, $\mathrm{C}_{2} \mathrm{H}_{4}(\mathrm{OH})\left(\mathrm{NH}_{2}\right)$ (Wako, 99\%). The $\mathrm{ZnO}$ NPs were synthesized in a similar manner to the methodology reported by Lin et al. but using a lower b.p. solvent, 2-aminoethanol (b.p. $170{ }^{\circ} \mathrm{C}$ ). ${ }^{10}$ Firstly, $0.49 \mathrm{mg}(0.1 \mathrm{~mol})$ of zinc(II) acetate $\mathrm{Zn}\left(\mathrm{CH}_{3} \mathrm{COO}\right)_{2}$ was added to 2-aminoethanol $(100 \mathrm{ml})$ and heated up to $160^{\circ} \mathrm{C}$ in an oil bath and the solution was stirred and refluxed for 1 hour under isothermal treatment. The purpose of reflux was to remove any by-products such as water or acetic acid produced during the reaction. After 1 hour, the resulting solution was cooled to room temperature. The solution was then centrifuged for 30 minutes to remove precipitates. The supernatant contained well-dispersed $\mathrm{ZnO}$ nanoparticles with an average size of $2.5 \mathrm{~nm}$, as observed from TEM. This supernatant was collected as the product and was stable for at least 6 months.

For the chemical synthesis of ZnO nanoparticles NPs in ethylene glycol, zinc(II) acetate, $\mathrm{Zn}\left(\mathrm{CH}_{3} \mathrm{COO}\right)_{2}$ (Wako, 99\%) and ethylene glycol, $\mathrm{C}_{2} \mathrm{H}_{4}(\mathrm{OH})_{2}$ (Wako, 99.0\%) were used. The $\mathrm{ZnO}$ NPs were synthesized in the same manner as the ZnO NPs in 2aminoethanol as aforementioned.

\section{Preparation of ZnO sol-gel films}

The ZnO sol-gel films were prepared using the method reported by Heeger and co-workers. ${ }^{4 b, 13 b}$ A $0.1 \mathrm{M}$ solution of zinc acetate dihydrate $\left[\mathrm{Zn}\left(\mathrm{CH}_{3} \mathrm{COO}\right) \cdot\left(2 \mathrm{H}_{2} \mathrm{O}\right]\right.$ (Wako, $\left.99.0 \%\right)$ in ethanol (Wako, 99.5\%) was prepared and then subjected to rigorous stirring for $2-3 \mathrm{~h}$ at $80{ }^{\circ} \mathrm{C}$. Next, an ethanolamine stabilizer ( $28 \%$ in weight) was added and the solution was left stirring for a further $12-15 \mathrm{~h}$ at $60^{\circ} \mathrm{C}$.

\section{Device fabrication}

ITO substrates $\left(22 \times 38 \mathrm{~mm}^{2}\right)$ with a sheet resistance of $6 \Omega$ per square (Kuramoto Co., Ltd.) were first etched using $\mathrm{Zn}$ and $1 \mathrm{M}$ $\mathrm{HCl}$, followed by sonicating the substrates sequentially in cleaning surfactants (Semi Clean, M-Lo), water, acetone and 2isopropanol for 15 minutes each. The substrates were then dried in an oven at $70{ }^{\circ} \mathrm{C}$. Prior to ZnO deposition, ITO substrates were exposed to $\mathrm{UV} / \mathrm{O}_{3}$ for $30 \mathrm{~min}$. ZnO NPs in 2aminoethanol were then deposited onto ITO substrates through a cellulose acetate filter $(0.45 \mu \mathrm{m}$ pore size) by spin coating at a spin speed of $950 \mathrm{rpm}$ for 30 seconds followed by $5000 \mathrm{rpm}$ for a further 30 seconds to remove the remnant solvent. The thickness of the ZnO film was below the resolution of the surface profilometer and estimated to be less than $20 \mathrm{~nm}$. Next the samples (where applicable) were annealed at temperatures between $120{ }^{\circ} \mathrm{C}$ and $210{ }^{\circ} \mathrm{C}$ for $1 \mathrm{~h}$. Sol-gel $\mathrm{ZnO}$ films were prepared by spin-coating the precursor solution at $3000 \mathrm{rpm}$ for $45 \mathrm{~s}$. The films were then annealed at $200{ }^{\circ} \mathrm{C}$ for $1 \mathrm{~h}$.

P3HT:mix-PCBM devices were fabricated in the following manner. A poly(3-hexylthiophene) (P3HT, regioregular, Sigma 
Aldrich Chemical Co., Inc.) and mix-PCBM (Frontier Carbon Co., Nanom spectra E124) solution with a donor : acceptor ratio of $5: 3$ and a concentration of $40 \mathrm{mg} \mathrm{ml}^{-1}$ was prepared in ortho-dichlorobenzene (anhydrous, 99\%, Sigma Aldrich Chemical Co., Inc.). The solution was left stirring for $2 \mathrm{~h}$ at $65^{\circ} \mathrm{C}$. The solution was then spin-coated on the $\mathrm{ZnO}$ layers at a speed of $850 \mathrm{rpm}$ for $60 \mathrm{~s}$ to give films of approximately $300 \mathrm{~nm}$. The films were then immediately placed in a Petri-dish for 40 minutes to allow slow evaporation of the solvent. A poly-(3,4ethylenedioxythiophene)-polystyrenesulfonic acid (PEDOT:PSS) dispersion in water (Clevios P VP, Heraeus Precious Metals $\mathrm{GmbH} \& \mathrm{Co}$.) containing $0.5 \mathrm{wt} \%$ polyoxyethylene(6) tridecyl ether (Sigma Aldrich Chemical Co., Inc.) was spin-coated on top of the active layer to form the hole transport layer with a $30 \mathrm{~nm}$ thickness. An approximately $200 \mathrm{~nm}$ thick Au layer was thermally evaporated at a pressure of $3 \times 10^{-3} \mathrm{~Pa}$, with the use of a shadow mask, which defined the device active area as $1 \mathrm{~cm}^{2}$. Finally, the devices were heated on a hot plate in air at a temperature of $150{ }^{\circ} \mathrm{C}$ for $5 \mathrm{~min}$. All processes, except for $\mathrm{Au}$ deposition, were performed in air and the devices were not encapsulated.

SQ:PC ${ }_{71} \mathrm{BM}$ devices were fabricated on both $\mathrm{ZnO} \mathrm{NP}$ and solgel films from a $20 \mathrm{mg} \mathrm{m}{ }^{-1} \mathrm{CHCl}_{3}$ solution, where the $\mathrm{SQ}: \mathrm{PC}_{71} \mathrm{BM}$ weight ratio was $1: 5$. The solution was spin-coated at $3000 \mathrm{rpm}$ for $60 \mathrm{~s}$ inside a $\mathrm{N}_{2}$ filled glovebox and the films were then annealed at $70{ }^{\circ} \mathrm{C}$ for $10 \mathrm{~min}$. Following annealing, the films were transferred, without exposure to air, to a vacuum chamber, where $\mathrm{MoO}_{3}(8 \mathrm{~nm})$ and $\mathrm{Au}(100 \mathrm{~nm})$ were deposited by thermal evaporation. Devices were encapsulated before measuring their $J-V$ curves. SQ was purchased from Sigma Aldrich and recrystallized by the slow diffusion of $\mathrm{MeOH}$ in a saturated solution of SQ in chloroform, following a previously reported method. ${ }^{14} \mathrm{PC}_{71} \mathrm{BM}$ was bought from Solenne and was used as received.

\section{Photovoltaic characterization}

Current-voltage $(J-V)$ characteristics were measured using a software-controlled source meter (Keithley 2400) under dark conditions and 1 Sun AM 1.5 G simulated sunlight irradiation $\left(100 \mathrm{~mW} \mathrm{~cm}^{-2}\right)$ using a solar simulator (EMS-35AAA, Ushio Spax Inc.), which was calibrated using a silicon diode (BS-520BK, Bunkyokeiki).

\section{Surface characterization}

AFM topography images were recorded using a Bruker Multimode atomic force microscope operating in tapping mode. Silicon AFM probes were used that had a nominal frequency of $70 \mathrm{kHz}$. XPS measurements were carried out on a JEOL photoelectron spectrophotometer (JPS-9010 MC) using a Mg-K $\alpha$ X-ray source and was calibrated using the $\mathrm{C} 1 \mathrm{~s}$ peak of graphite (284.8 $\mathrm{eV}$ ) as a reference.

\section{Acknowledgements}

This work was supported by the Funding Program for NextGeneration World-Leading Researchers (GR-30).

\section{Notes and references}

1 S. B. Darling and F. You, RSC Adv., 2013, 3, 17633-17648.

2 (a) M. A. Green, K. Emery, Y. Hishikawa, W. Warta and E. D. Dunlop, Progress in Photovoltaics: Research and Applications, 2014, 22, 1-9; (b) J. You, L. Dou, K. Yoshimura, T. Kato, K. Ohya, T. Moriarty, K. Emery, C.-C. Chen, J. Gao, G. Li and Y. Yang, Nat. Commun., 2013, 4, 1446.

3 D. M. Tanenbaum, M. Hermenau, E. Voroshazi, M. T. Lloyd, Y. Galagan, B. Zimmermann, M. Hosel, H. F. Dam, M. Jorgensen, S. A. Gevorgyan, S. Kudret, W. Maes, L. Lutsen, D. Vanderzande, U. Wurfel, R. Andriessen, R. Rosch, H. Hoppe, G. Teran-Escobar, M. Lira-Cantu, A. Rivaton, G. Y. Uzunoglu, D. Germack, B. Andreasen, M. V. Madsen, K. Norrman and F. C. Krebs, RSC Adv., 2012, 2, 882-893.

4 (a) Z. He, C. Zhong, S. Su, M. Xu, H. Wu and Y. Cao, Nat. Photonics, 2012, 6, 591-595; (b) A. K. K. Kyaw, D. H. Wang, V. Gupta, J. Zhang, S. Chand, G. C. Bazan and A. J. Heeger, Adv. Mater., 2013, 25, 2397-2402.

5 T. Matsushima, Y. Kinoshita and H. Murata, Appl. Phys. Lett., 2007, 91, 253504.

6 Y. Matsuo, J. Hatano, T. Kuwabara and K. Takahashi, Appl. Phys. Lett., 2012, 100, 063303.

7 (a) T. Kuwabara, H. Sugiyama, M. Kuzuba, T. Yamaguchi and K. Takahashi, Org. Electron., 2010, 11, 1136-1140; (b) P. P. Boix, J. Ajuria, I. Etxebarria, R. Pacios, G. GarciaBelmonte and J. Bisquert, J. Phys. Chem. Lett., 2011, 2, 407411; (c) M. Bolognesi, A. Sanchez-Diaz, J. Ajuria, R. Pacios and E. Palomares, Phys. Chem. Chem. Phys., 2011, 13, 61056109; (d) T. Kuwabara, T. Nakashima, T. Yamaguchi and K. Takahashi, Org. Electron., 2012, 13, 1136-1140; (e) M. A. Ibrahem, H.-Y. Wei, M.-H. Tsai, K.-C. Ho, J.-J. Shyue and C. W. Chu, Sol. Energy Mater. Sol. Cells, 2013, 108, 156-163.

8 S. Alem, J. Lu, R. Movileanu, T. Kololuoma, A. Dadvand and Y. Tao, Org. Electron., 2014, 15, 1035-1042.

9 Y. Santo, I. Jeon, K. Sheng Yeo, T. Nakagawa and Y. Matsuo, Appl. Phys. Lett., 2013, 103, 073306.

10 K.-F. Lin, H.-M. Cheng, H.-C. Hsu, L.-J. Lin and W.-F. Hsieh, Chem. Phys. Lett., 2005, 409, 208-211.

11 (a) Y. Ho Huh, B. Park and I. Hwang, J. Appl. Phys., 2014, 115, 124504; (b) W. Tress, K. Leo and M. Riede, Adv. Funct. Mater., 2011, 21, 2140-2149; (c) A. Wagenpfahl, D. Rauh, M. Binder, C. Deibel and V. Dyakonov, Phys. Rev. B: Condens. Matter Mater. Phys., 2010, 82, 115306.

12 B. R. Lee, E. D. Jung, Y. S. Nam, M. Jung, J. S. Park, S. Lee, H. Choi, S.-J. Ko, N. R. Shin, Y.-K. Kim, S. O. Kim, J. Y. Kim, H.-J. Shin, S. Cho and M. H. Song, Adv. Mater., 2014, 26, 494-500.

13 (a) L.-J. Meng, C. P. Moreira de Sá and M. P. dos Santos, Appl. Surf. Sci., 1994, 78, 57-61; (b) Y. Sun, J. H. Seo, C. J. Takacs, J. Seifter and A. J. Heeger, Adv. Mater., 2011, 23, 1679-1683; (c) X. Q. Wei, B. Y. Man, M. Liu, C. S. Xue, H. Z. Zhuang and C. Yang, Phys. Rev. B: Condens. Matter Mater. Phys., 2007, 388, 
145-152; (d) E. De la Rosa, S. Sepúlveda-Guzman, B. ReejaJayan, A. Torres, P. Salas, N. Elizondo and M. J. Yacaman, J. Phys. Chem. C, 2007, 111, 8489-8495.

14 M. Tian, M. Furuki, I. Iwasa, Y. Sato, L. S. Pu and S. Tatsuura, J. Phys. Chem. B, 2002, 106, 4370-4376.
15 G. D. Wei, S. Y. Wang, K. Renshaw, M. E. Thompson and S. R. Forrest, ACS Nano, 2010, 4, 1927-1934.

16 G. Chen, H. Sasabe, Z. Wang, X. Wang, Z. Hong, J. Kido and Y. Yang, Phys. Chem. Chem. Phys., 2012, 14, 14661-14666. 